\title{
SISTEM INFORMASI PEMBERITAHUAN ABSENSI SISWA KEPADA ORANG TUA MENGGUNAKAN SMS GATEWAY BERBASIS WEB DI SMP NEGERI 4 PAREPARE
}

\author{
SYAMSUMARLIN TAHA ${ }^{1}$, MUH.RAIS ${ }^{2}$ \\ Fakultas Teknik \& Informatika, ${ }^{1,2}$ \\ Universitas Patria Artha \\ Email: syamsumarlintaha@gmail.com¹, Muh.raisazis@gmail.com²
}

\begin{abstract}
ABSTRAK
Tujuan penelitian ini adalah untuk menghasilkan sistem informasi pemberitahuan absensi siswa kepada orang tua menggunakan sms gateway berbasis web di SMP Negeri 4 Parepare. Penelitian ini merupakan jenis penelitian yang menggunakan metode Research and Development $(R \& D)$ dengan menggunakan prosedur pengembangan Prototype dan pengujian kualitas perangkat lunak berdasar ISO 9126 dengan empat karakteristik, yakni karakteristik functionality, reliability, portability dan usability. Hasil penelitian ini adalah sebuah sistem pemberitahuan absensi siswa kepada orang tua menggunakan sms gateway berbasis web di SMP Negeri 4 Parepare dengan hasil pengujian dari functionality untuk sub karakteristik accurancy and suitability menunjukkan tingkat kelayakan 100\%, untuk sub karakteristik security sistem dinyatakan aman dari malware, website blacklisting, injected SPAM, defacement, dan SQLInjection. Hasil pengujian reliability sistem dinyatakan sangat baik dengan tingkat kelayakan 100\%, Pengujian portability menunjukan bahwa sistem ini mendukung desktop dan OS mobile, dan pada pengujian usability menunjukan tingkat kelayakan $84.90 \%$.
\end{abstract}

Kata Kunci: Pemberitahuan absensi siswa, OS, Web Sistem.

\section{PENDAHULUAN}

Perkembangan teknologi Internet yang pesat telah memicu munculnya berbagai aplikasi baru termasuk di bidang teknologi informasi. Website adalah salah satu revolusi dibidang informasi berbasis teknologi Internet. Website diharapkan dapat dijadikan alternatif bagi pengembangan sistem informasi yang lebih efektif dan efesien dengan biaya yang lebih rendah di masa mendatang. Hal ini dapat berjalan lancar apabila ada suatu jaringan komputer. 
Jaringan Komputer adalah sekelompok komputer otonom yang dihubungkan satu dengan yang lainya,dengan menggunakan protocol komunikasi melalui media transmisi atau media komunikasi sebagai sarana untuk mengalirkan sebuah informasi. Dengan demikian diharapkan informasi tersebut dapat diakses oleh pengguna kapan saja secara online melalui jaringan komputer yang sudah terkoneksi internet. Fungsi lain jaringan komputer adalah menyediakan fasilitas untuk melakukan sharing dalam menggunakan hardware maupun software.

Informasi adalah suatu hasil dari pengolahan data yang penting bagi penerimanya. Untuk mendapatkan dan menghasilkan Informasi, komputer dan teknologi adalah suatu alat bantu yang tepat.kebutuhan akan informasi mendorong adanya ketersediaan sarana seperti pemasangan jaringan internet di tempat-tempat umum khususnya sekolah sebagai salah satu fasilitas yang sangat mendukung dalam hal penyajian informasi, oleh karena itu sekolah yang sudah terkoneksi internet dapat memanfaatkan fasilitas ini sebagai media informasi yang cepat,akurat dan up to date dalam menyajikan informasi yang diperlukan. Website diharapkan dapat membantu masyarakat pada umumnya dan sekolah pada khususnya untuk melakukan penyebaran informasi dengan cepat,murah,dan efektif.

Absensi merupakan kegiatan yang harus dimiliki oleh setiap orang agar dapat membantu dalam melakukan aktivitas sehari-hari. Terlebih lagi sebuah instansi atau lembaga yang memiliki agenda-agenda penting yang harus diselesaikan secara teratur dan rapi.

Absensis siswa di SMPN 4 Parepare adalah salah satu unsur penting dalam proses absensi siswa. Jadwal absensi yang baik memiliki manfaat pada sekolah setiap harinya untuk setiap tingkatan tanpa mengalami kendala dalam proses absensi. Salah satu kegunaan absensi ini untuk memudahkan guru dalam melakukan absensi dan pembuatan tolak ukur ke depan guna pemberian ilmu yang baik.

Berdasarkan hasil observasi awal yang telah dilakukan di SMPN 4 Parepare pengambilan data absensi ini dilakukan secara manual dan pengolahan data absen 
juga manual melihat kondisi seperti ini proses absensi yang dilakukan memiliki kekurangan seperti data tidak valid ketika data yang masuk salah hilang atau rusaknya data yang ada serta kurang efisien dan efektif pada pengolahan data.

\section{II.METODE PENELITIAN}

Model Pengembangan sistem pemberitahuan absensi siswa ini menggunakan metode penelitian dan pengembangan (research and development). Penelitian dan pengembangan adalah metode penelitian yang digunakan untuk menghasilkan produk tertentu, dan menguji keefektifan produk tersebut. Hasil produk tertentu digunakan penelitian yang bersifat analisis kebutuhan dan untuk menguji keefektifan produk tersebut supaya dapat berfungsi di masyarakat luas, maka diperlukan penelitian untuk menguji keefektifan produk tersebut (Sugiyono, 2013).

\section{Desain Ujicoba}

\section{a. Data Flow Diagram (DFD)}

DFD merupakan representasi grafik dalam menggambarkan arus data sistem secara terstruktur dan jelas sehingga dapat menjadi sarana dokumentasi yang baik.

1) Context Diagram (DFD Level 0)

Diagram ini menggambarkan rancangan global/keseluruhan dari proses yang ada pada DFD. Gambar 1. berikut ini merupakan tampilan dari context diagram sistem yang dirancang.

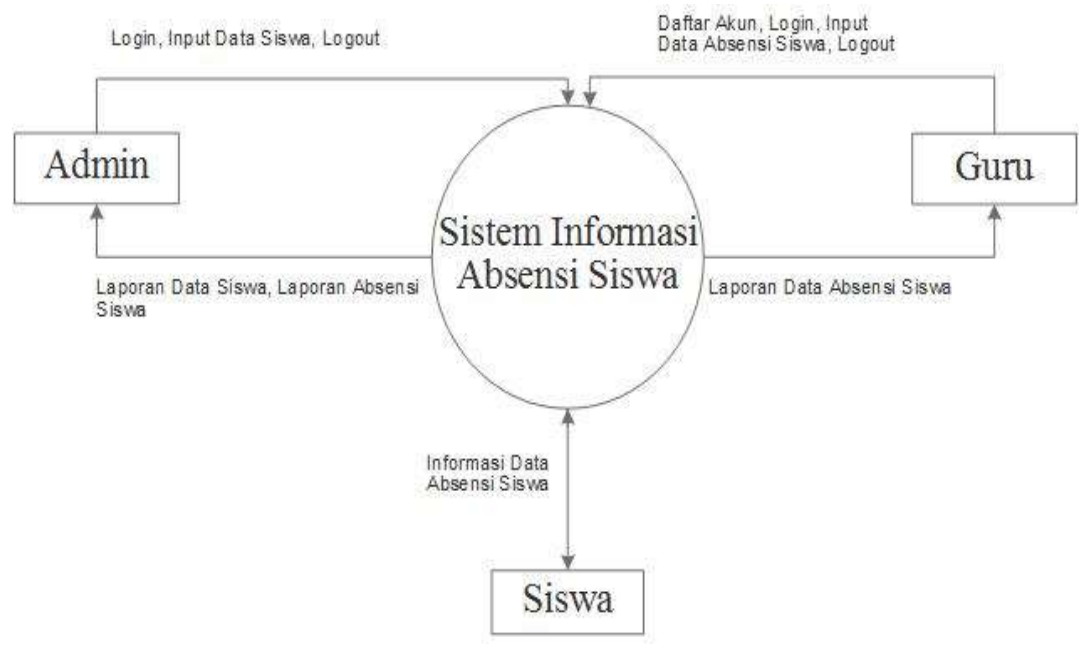

Gambar 1. Context Diagram (DFD Level 0) 
Volume 5 Nomor. 1, April 2020

P-ISSN : 2541-1179, E-ISSN : 2581-1711

Ojs :http://journal.uin-alauddin.ac.id/index.php/instek/index

Email : instek@uin-alauddin.ac.id

\section{b.Perancangan Flowchart system}

Bagan alir sistem (system flowchart) merupakan bagan yang menunjukkan arus pekerjaan secara keseluruhan dari sistem. Bagan ini menjelaskan urut-urutan dari prosedurprosedur yang ada di dalam sistem. Bagan alir sistem menunjukkan apa yang dikerjakan di sistem.

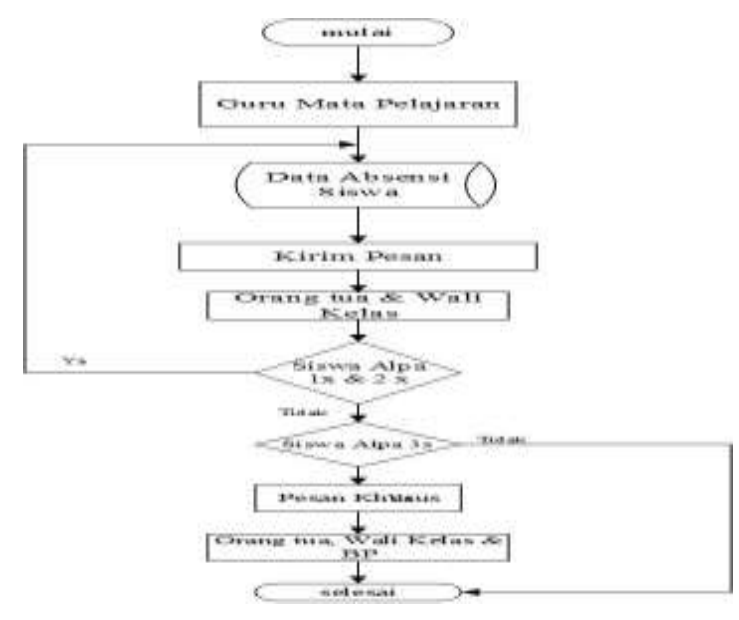

Gambar 2. Flowchart Sistem

\section{III.HASIL PENELITIAN}

Hasil penelitian yang dihasilkan adalah berupa rancangan sistem informasi absensi guru dan siswa yang dibuat dengan menggunakan bahasa pemrograman Hypertext Preprocessor (PHP), Hypert Text Markup Language (HTML), Cascading Style Sheet (CSS), dan javascript . Sistem ini bertujuan untuk membantu guru dalam melakukan absensi sehingga proses absensi guru dan absensi siswa menjadi lebih efektif dan efisien.

Kegiatan awal dalam pembuatan sistem ini meliputi perencanaan, selanjutnya mendesain sistem yang kemudian divalidasi dan diujicoba kepada objek peneliti. Tahap validasi dan uji coba bertujuan untuk mengetahui kelayakan dan kelemahan sistem sebelum diimplementasikan. 
Pengimplementasian sistem dilakukan setelah sistem divalidasi oleh ahli sistem dengan hasil yang berada pada kategori layak atau sangat layak digunakan. Sistem ini akan diimplementasikan pada SMA Negeri 1 Tellulimpoe Kabupaten Sinjai. SMP Negeri 4 Parepare.

\section{a. Interface umum/Publik}

\section{1) Halaman Home (Beranda)}

Halaman utama (home) merupakan halaman yang mengarahkan guru dan admin untuk login disistem ini dan halaman untuk siswa melihat informasi singkat tentang absensinya.

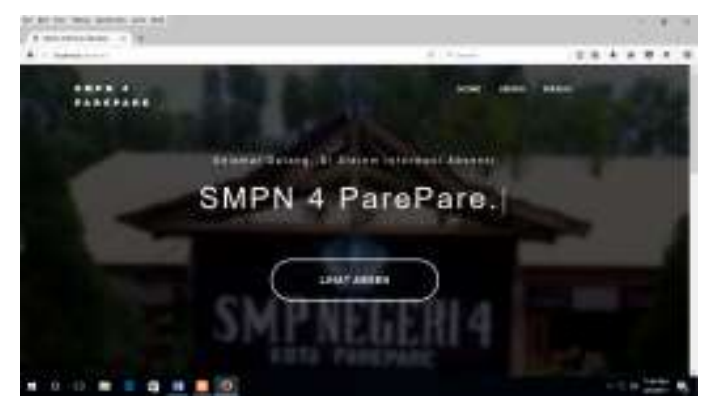

\section{Gambar 3.Menu Home}

\section{2) Halaman Login}

Menu login akan mengarahkan guru dan admin untuk memasukkan username dan password yang telah diperoleh sebelumnya yaitu guru dengan username dan password yang telah diaktifkan oleh admin.

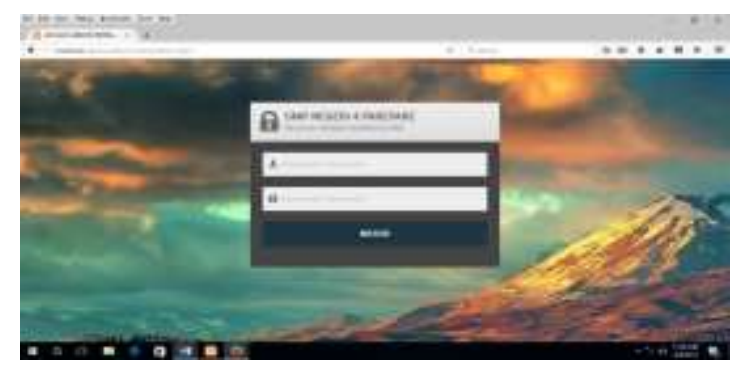

Gambar 4.Login Guru Dan Admin 
Volume 5 Nomor. 1, April 2020

P-ISSN : 2541-1179, E-ISSN : 2581-1711

Ojs :http://journal.uin-alauddin.ac.id/index.php/instek/index

Email : instek@uin-alauddin.ac.id

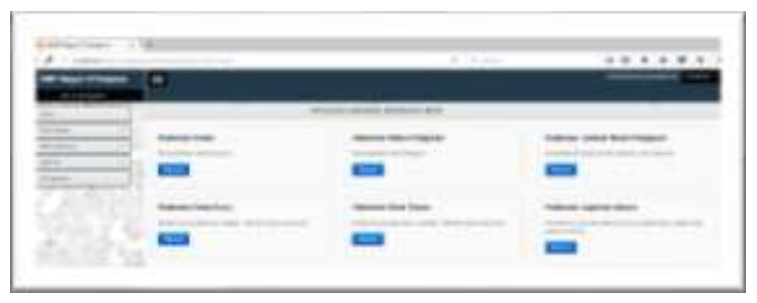

Gambar 5.Menu Awal Admin

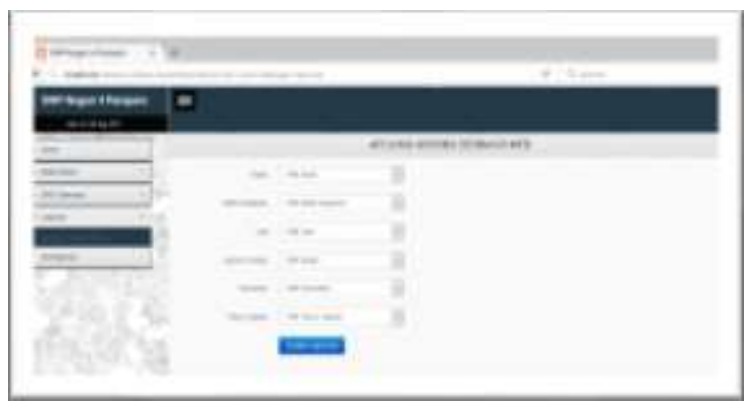

Gambar 6. Halaman cetak Laporan Absensi Siswa

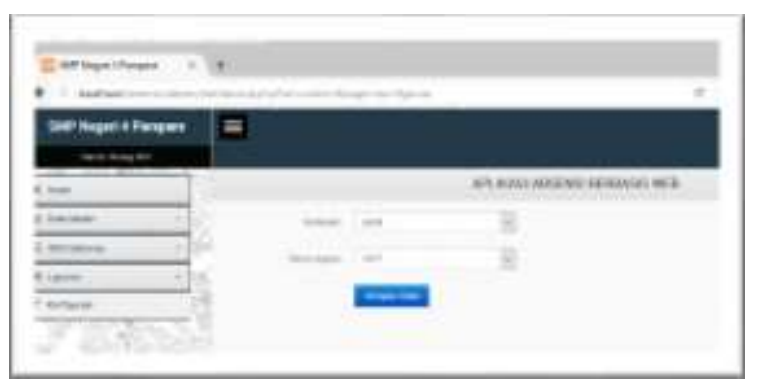

Gambar 7.Halaman Konfigurasi

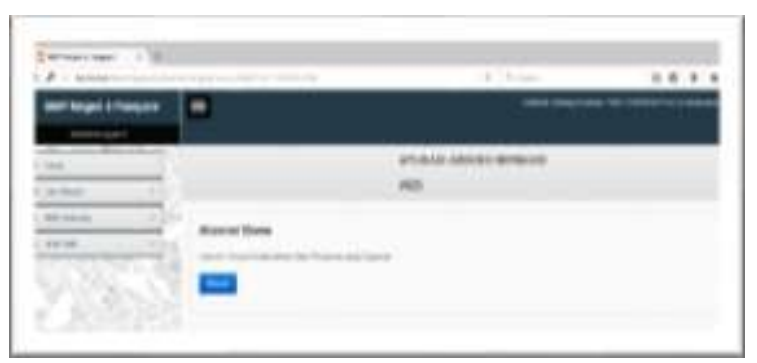

Gambar 8. Halaman Awal Guru 
Volume 5 Nomor. 1, April 2020

P -ISSN : 2541-1179, E-ISSN : 2581-1711

Ojs :http://journal.uin-alauddin.ac.id/index.php/instek/index Email : instek@uin-alauddin.ac.id

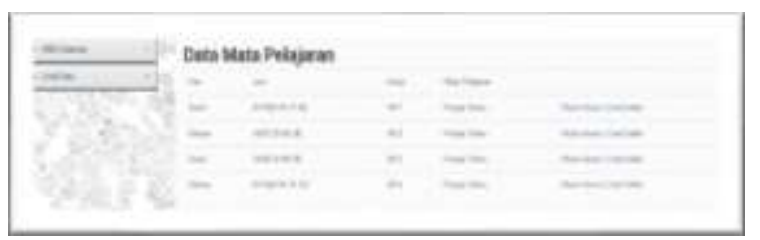

Gambar 9. Halaman Absensi Siswa

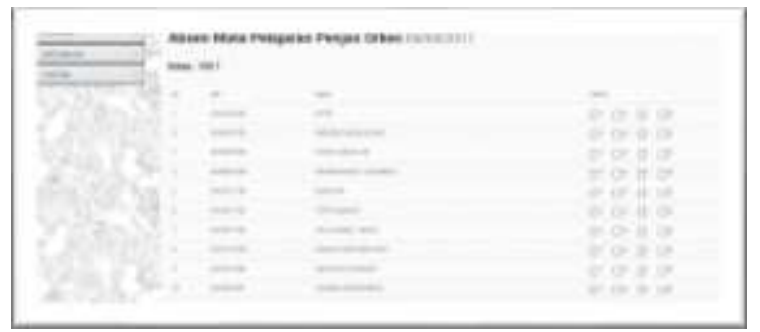

Gambar 10.Halaman Form Absensi Siswa

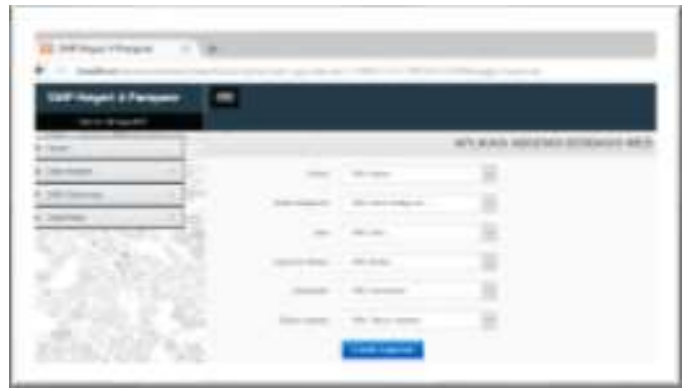

Gambar 11.Halaman Lihat data absen siswa

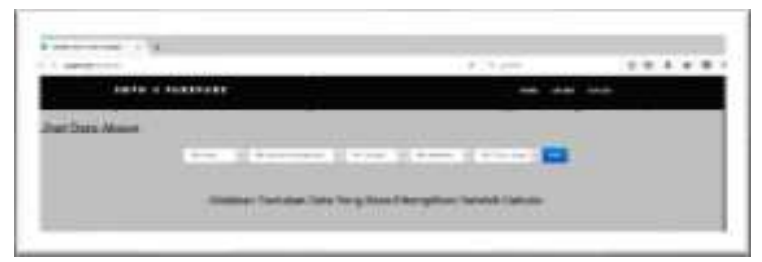

Gambar 12.Halaman Lihat data absensi (Siswa)

\section{PEMBAHASAN}

Penelitian ini menghasilkan suatu rancangan sistem yang bertujuan untuk membantu absensi di SMP Negeri 4 Parepare yaitu memaksimalkan absensi dengan menerapkan sistem absensi berbasis web. Absensi yang sebelumnya masih manual menjadi absensi berbasis komputer. Sistem ini 
Volume 5 Nomor. 1, April 2020

P -ISSN : 2541-1179, E-ISSN : 2581-1711

Ojs :http://journal.uin-alauddin.ac.id/index.php/instek/index

Email : instek@uin-alauddin.ac.id

memberikan kemudahan bagi admin, guru dan siswa dari proses absen hingga proses cetak daftar absensi yang jika ditinjau dari sisi sumber daya dan waktu akan lebih hemat, efektif, dan efisien.

Sistem Absensi Siswa berbasis web SMP Negeri 4 Parepare ini dirancang menggunakan bahasa pemrograman PHP:Personal Home Page Hypertext Preprocessor (PHP), Hypert Text Markup Language (HTML), javascript, dan framework CSS yaitu boostrap sehingga setiap halaman pada sistem memiliki desain yang responsif dan mudah digunakan.

Berdasarkan hasil pengujian validitas oleh dua ahli, maka sistem ini layak untuk digunakan dengan sedikit rivisi. Pengujian selanjutnya yaitu pengujian sistem dengan menggunakan standar ISO 9126 sebagai acuan pengujian. Pengujian dengan standar ISO 9126 pada penelitian ini dibatasi hanya menggunakan 4 aspek, yaitu Functionality, Reliability, Portability dan Usability.

Pengujian Functionality dilakukan dengan memberikan instrumen kepada ahli, yang memiliki skala sangat baik dikarenakan dari 57 butir peryataan dalam instrumen dianggap dapat berfungsi dengan baik. Pengujian reliability pada sistem informasi salah satunya dengan metode stresss testing. Stress Testing adalah salah satu metode pengujian software yang menentukan katahanan suatu software dengan mengujinya diluar batas penggunaan yang normal. Stress testing dapat diuji dengan menggunakan web testing tool yang bernama Webserver Stress Tool 8, yang memiliki rasio keberhasilan 100\% pada sistem informasi absensi guru dan siswa berbasis web di SMP Negeri 4 Parepare.

Pengujian Portability dari sistem ini menggunakan bantuan dari web testing tool yakni browserstack.com dimana pengetesan dilakukan dengan Cross Browser Testing atau pengecekan sistem dengan menggunakan berbagai browser pada desktop dan OS mobile.

Pengujian Usability merupakan faktor penting dalam pengembangan suatu website dikarenakan suatu website diciptakan untuk memenuhi kebutuhan 
Volume 5 Nomor. 1, April 2020

P -ISSN : 2541-1179, E-ISSN : 2581-1711

Ojs :http://journal.uin-alauddin.ac.id/index.php/instek/index

Email : instek@uin-alauddin.ac.id

pengguna, sehingga kemudahan pengguna dalam menggunakan sistem harus diutamakan. Pengujian usability pada sistem ini menggunakan kuesioner yang berisi 19 pertanyaan mengenai Komputer software. Kuesioner ini dibagikan kepada 2 Admin 18 Guru dan 40 Siswa dan 10 Orang tua SMP Negeri 4 Parepare dan mendapatkan tingkat kelayakan $84.90 \%$.

Berdasarkan hasil dari penelitian Rancang Bangun Sistem Informasi Absensi Siswa Menggunakan SMS Gateway Berbasis Web di SMP Negeri 4 Parepareini setelah divalidasi dan dilakukan pengujian dengan menggunakan standar ISO 9126 ditinjau dari segi functionality, reliability, portability, maupun usability dapat disimpulkan bahwa sistem informasi dapat digunakan oleh pengguna akhir.

\section{IV.KESIMPULAN}

Berdasarkan pembahasan yang telah diuraikan, dapat diambil kesimpulan bahwa :

1. Sistem informasi pemberitahuan absensi siswa menggunakan SMS Gateway berbasis web dirancang dengan menggunakan bahasa pemrograman Hypertext Preprocessor (PHP), Hypert Text Markup Language (HTML), javascript, dan framework CSS yaitu boostrap sehingga setiap halaman pada sistem memiliki desain yang responsif dan mudah digunakan. Pengujian sistem dilakukan dengan standar ISO 9126 dengan empat karakteristik yakni functionality, realibility, portability dan usability.

2. Tanggapan pihak sekolah terhadap Sistem Informasi Pemberitahuan Absensi Siswa kepada Orang Tua Menggunakan SMS Gateway berada dikategori sangat layak dengan jumlah presentasi $85 \%$.

3. Tanggapan orang tua siswa terhadap Sistem Informasi Pemberitahuan Absensi Siswa kepada Orang Tua Menggunakan SMS Gateway berada dikategori sangat layak dengan jumlah presentasi $100 \%$. 


\section{DAFTAR PUSTAKA}

Al Bahra Bin Ladjamuddin. 2013.Analisis dan Desain Sistem Informasi. Yogyakarta:Graha Ilmu.

Fahrurozi. 2011. Sistem Informasi Penjadwalan Mata Kuliah pada International Programs Fakultas Sains dan Teknologi UIN Hidayatullah Jakarta Berbasis Website. Tesis tidak dipublikasikan. Jakarta.Universitas UIN Hidayatullah Jakarta.

Jogiyanto, 2005. Analisis dan Desain Sistem Informasi, Andi: Yogyakarta.

Kristanto. 2013. BAB II Widuri Skripsi, diakses di http://widuri.raharja.info/ index.php?title=BAB_II_Widuri_Skripsi diakses 16 Januari 2017.

McLeod, Jr. 2001. Sistem Informasi Manajemen. Jakarta: PT Prenhallindo

Nugroho, Bunafit. 2013. Membuat Aplikasi Web Penggajian dengan PHP, MySQL dan Dreamweaver. Yogyakarta: Alif Media.

Purwanto, Yudhi. 2011. Pemrograman Web dengan PHP. Jakarta:Elex Media Komputindo.

Rohmi Julia. (2012). Pengembangan aplikasi Amdroid sebagai media pembelajaran matematika pada materi dimensi tiga untuk siswa SMA kelas X. FMIPA UM

Shaweddy. 2011. BAB 1,(http://ejournal.uajy.ac.id/1692/2/1TF05139.pdf, diakses tanggal 27 Januari 2017).

Sugiyono. 2013. Metode Penelitian Kuantitatif Kualitatif dan $R \& D$. Bandung : Alfabeta

Yakub.2012.Pengantar Sistem Informasi.Yogyakarta: Graha Ilmu 